\title{
Invitation: Special Issue: Bringing Dialogism to Bear on the Early Years
}

\author{
Jayne White
}

(C) Springer Science+Business Media Dordrecht 2013

The dialogic philosophy of Mikhail Bakhtin and members of his circle has been applied, with increasing fervor, to the field of education. Dialogism is now viewed as a significant field of epistemology and ontological inquiry that has relevance to diverse forms of learning and development, emotionality and agency, encompassing language(s) in its fullest sense. Early years scholars are invited to submit papers to a special issue that will explore the potential of dialogism in the lives of very young children, and those who share in these. Papers may have employed dialogic methodologies and/or explore dialogic concepts such as chronotope, heteroglossia, carnivalesque, authorship, and polyphony (to name but a few). The journal will provide a means of exploring these and other aspects of dialogism and its dynamic contribution to 21 st century ECE.

Please send a 500 word abstract, with references, not later than March 1st, 2014. Abstracts should be sent to the editor responsible for this special issue: Dr Jayne Whitewhiteej@waikato.ac.nz

\footnotetext{
J. White $(\bowtie)$

The University of Waikato, Waikato, New Zealand

e-mail: whiteej@waikato.ac.nz
} 